First Peoples Child \& Family Review

A Journal on Innovation and Best Practices in Aboriginal Child Welfare Administration,

\title{
Building a Collaborative Understanding of Pathways to Adolescent Alcohol Misuse in a Mi'kmaq Community: A Process Paper
}

\author{
Marc Zahradnik, Doreen Stevens, Sherry Stewart, M. Nancy Comeau, Christine \\ Wekerle and Christopher J. Mushquash
}

Volume 3, Number 2, 2007

Special Issue: Adolescent development, mental health, and promising research directions for Aboriginal youth

URI: https://id.erudit.org/iderudit/1069459ar

DOI: https://doi.org/10.7202/1069459ar

See table of contents

Publisher(s)

First Nations Child and Family Caring Society of Canada

ISSN

1708-489X (print)

2293-6610 (digital)

Explore this journal

Cite this article

Zahradnik, M., Stevens, D., Stewart, S., Comeau, M., Wekerle, C. \& Mushquash, C. (2007). Building a Collaborative Understanding of Pathways to Adolescent Alcohol Misuse in a Mi'kmaq Community: A Process Paper. First Peoples Child \& Family Review, 3(2), 27-36. https://doi.org/10.7202/1069459ar

\section{Article abstract}

In April of 2006, a team of researchers consisting of both university and community partners from a Mi'kmaq reserve in Nova Scotia began the data-collection phase of a high school-based research study that had been two years in planning. The study examines the possible relationships between youth-reported childhood maltreatment, posttraumatic stress disorder (PTSD) symptoms, depressive symptoms, alcohol misuse, and resiliency factors. The aim of the research study is to provide information about adolescent alcohol misuse that is of practical benefit to community-based service providers, and capable of making a scholarly contribution to the scientific study of the relations of anxiety/mood symptoms and addictive behaviours. The primary aim of this paper is to present both the context from which the project grew, and the steps involved in conducting research with our school partners and the community service providers. A secondary aim is to present some of the preliminary data from the study, with a specific focus on resiliency.
Copyright ( $)$ Marc Zahradnik, Doreen Stevens, Sherry Stewart, M. Nancy Comeau, Christine Wekerle, Christopher J. Mushquash, 2007
This document is protected by copyright law. Use of the services of Érudit (including reproduction) is subject to its terms and conditions, which can be viewed online.

https://apropos.erudit.org/en/users/policy-on-use/ 


\title{
Building a Collaborative Understanding of Pathways to Adolescent Alcohol Misuse in a Mi'kmaq Community: A Process Paper
}

\author{
Marc Zahradnik $^{\mathrm{a}}$, Doreen Stevens ${ }^{\mathrm{b}}$, Sherry Stewart ${ }^{\mathrm{a}, \mathrm{c}}$, M. Nancy Comeau ${ }^{\mathrm{a}, \mathrm{d}}$, Christine \\ Wekerle $^{\mathrm{e}}$ and Christopher Mushquash ${ }^{\mathrm{a}}$
}

aDepartment of Psychology, Dalhousie University, Halifax, NS, Canada

${ }^{b}$ Department of Psychology, Mount Saint Vincent University, Halifax, NS, Canada

'Department of Psychiatry, Dalhousie University, Halifax, NS, Canada

${ }^{d}$ Adjunct Professor, School of Health and Human Performance, Faculty of Health Professions and Research Fellow, Institute of Integrative Science and Health, Cape Breton University

${ }^{e}$ Faculty of Education, Department of Psychology, University of Western Ontario, London, ON, Canada

\section{Introduction}

Childhood maltreatment ${ }^{1}$ and subsequent alcohol misuse are frequently linked together across cultural groups. They are a concern for most Canadian communities. Although there is very little published literature that either reports on or explores the connection between child maltreatment and alcohol misuse in First Nations' communities, the published research that is available seems to suggest that rates of violence exposure and alcohol use/misuse are high in some communities (Health Canada, 2003). For example,

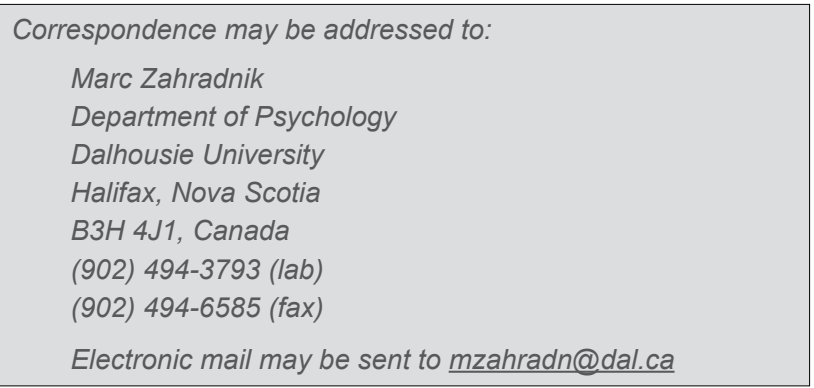

\begin{abstract}
In April of 2006, a team of researchers consisting of both university and community partners from a Mi'kmaq reserve in Nova Scotia began the data-collection phase of a high school-based research study that had been two years in planning. The study examines the possible relationships between youth-reported childhood maltreatment, posttraumatic stress disorder (PTSD) symptoms, depressive symptoms, alcohol misuse, and resiliency factors. The aim of the research study is to provide information about adolescent alcohol misuse that is of practical benefit to community-based service providers, and capable of making a scholarly contribution to the scientific study of the relations of anxiety/mood symptoms and addictive behaviours. The primary aim of this paper is to present both the context from which the project grew, and the steps involved in conducting research with our school partners and the community service providers. A secondary aim is to present some of the preliminary data from the study, with a specific focus on resiliency.
\end{abstract}

the 1991 Statistics Canada Aboriginal People's Survey revealed that $62 \%$ of First Nations respondents reported that alcohol was a problem in their community, while $39 \%$ of respondents reported that family violence was a problem in their community (Indian and Northern Affairs Canada, 2004). It is recognized, though, that a complex web of ecological factors support the maltreatment-substance abuse issue. For example, a study by Blackstock, Trocmé, and Bennett (2004) found that Aboriginal families, compared to non-Aboriginal families, face worse socioeconomic conditions, are more often investigated because of neglect, and report higher rates of substance abuse. Poor socioeconomic conditions, substance abuse, and poor parenting skills (e.g., neglect and abuse), to name a few, are problems that are now well understood to be consequences of a history of coloni- 


\section{Author Notes}

This project was supported in part by a Canadian Institutes of Health Research New Emerging Team (CIHR NET) grant held by Drs. Christine Wekerle and Sherry Stewart, as well as an Atlantic Aboriginal Health Research Program (AAHRP), a CIHR-Institute of Aboriginal Peoples Health (CIHR-IAPH) funded Aboriginal Capacity and Developmental Research Environment (ACADRE) research allowance held by Marc Zahradnik. Mr. Zahradnik is also funded by an AAHRP graduate student award. Dr. Stewart is supported through an Investigator Award from the CIHR and a Killam Research Professorship from the Faculty of Science at Dalhousie University. Christopher Mushquash is supported by a University of Toronto/McMaster University Indigenous Health Research Development Program Graduate Scholarship, funded by the CIHR-IAPH. The authors would like to thank Dr. M. Nancy Comeau for her assistance and support while at Dalhousie University; Dr. Comeau is now at Cape Breton University.

zation, as pointed out by the Royal Commission on Aboriginal People; a most pernicious manifestation of colonization that has had immeasurable deleterious consequences on Aboriginal health, culture, and identity, is the residential school system (Indian and Northern Affair Canada, 1996).

The residential school system failed miserably in its deplorable goal of attempting to "civilize" Aboriginal children. In its attempt "to transport Aboriginal children through the classroom to the desired assimilative destination," the system more often than not produced individuals who felt marginalized from both their home communities and the communities of their colonizers, leaving many with few constructive alternatives to a life of prostitution and/or alcoholism (Indian and Northern Affairs Canada, 1996). Furthermore, the structure sewed the seeds for generational cycles of family violence because these schools disrupted the transference of parenting skills from one generation to the next, so that many survivors, lacking the necessary parenting skills, came to rely on the lessons they learned at these schools: that adults often maintain power, control, and obedience through abuse (Indian and Northern Affairs Canada, 1996). Because so many cases of sexual and physical abuse went ignored and unhealed, giving rise to numerous unhealthy coping behaviours, including the perpetration of violence, such behaviours often became "normal" and were subsequently passed on to subsequent generations, resulting in intergenerational or multi-generational trauma (Wesley-Esquimaux \& Smolewski, 2004).

The authors of this paper recognize the historical and cultural roots to maltreatment-substance misuse problem in some Aboriginal communities, but the present study was not designed to test the contribution of these historical factors. Rather, our research team focused on the current circumstances of exposure to violence, psychological effects of such exposure to violence, and subsequent relations to alcohol misuse among teens living in an Aboriginal community today. Our school-based research study is attempting to not only make a contribution to an area that is presently lacking - the relationship between child maltreatment and alcohol misuse - but to also provide the community service providers with tailored evidence for intervention recommendations. As this study is on-going, the purpose of this paper is not to report on the final research findings, but to provide a brief summary of the research process. This shall include: 1) briefly describing the community; 2) briefly locating the purpose of the research within the community context; 3 ) briefly locating the purpose of the research within the scientific literature; 4) discussing the process of ethical approval and community consent; 5) discussing the implementation of the study; and 6) sharing some preliminary findings based on the information we have collected thus far.

\section{Community Organization}

The Mi'kmaq community is a self-governing First Nations Community. It is one of the largest First Nations communities in Atlantic Canada, and its origins go back to the first half of the 19th century, though it was not until the half way point of the 20th century that the community's population increased dramatically. Shortly thereafter, the community became selfgoverned by establishing its own Band Council. The community has its own Board of Education, Board of Health, local police, fire department, and ambulance service. 


\section{Community Context}

In the fall 2002, our research group was invited to the Atlantic Region First Nation community by the principal of the community high school and the detachment commander of the RCMP ${ }^{2}$ to discuss ways of dealing with issues of alcohol and other substance abuse among community youth. These discussions lead to further collaboration between members of our research team (led by post-doctoral fellow Dr. M. Nancy Comeau) and school staff (from two schools) and the eventual participation of community youth in the development of a culturally relevant early intervention program for alcohol misuse, entitled "Nemi'simk, Seeing Oneself" (see Mushquash et al., 2007; see also Comeau et al., 2005). The present study evolved from the voices of those adolescents who participated in "Nemi'simk."

From the qualitative data already collected about these adolescents' perceptions of their reasons for alcohol misuse (Comeau, Stewart, \& Collins, 2004), it appeared that themes of violence exposure and anger might be important contributing factors. Furthermore, the guidance counselor from one of the community schools, who also became a co-investigator of the present study, in a letter addressed to the Dalhousie Health Sciences Research Ethics Board, underscored the relevance of this project to her community when she noted that both she and her colleagues had observed a recent increase in disclosures and reports of childhood trauma.

Based on some of the findings of the previous work with the schools, and the observations of school guidance counselors and mental health professionals in the community, it was felt that a well-designed study might be able to shed some light on the possible relationship between maltreatment and adolescents' alcohol misuse. Furthermore, given the well-documented relationships between interpersonal violence, post-traumatic stress disorder (PTSD) symptoms, depressive symptoms, and alcohol and other substance misuse in non-Native populations (see reviews by Stewart, 1996, and Stewart \& Israeli, 2002), the em- pirical literature in this area helped ground our conceptualization of the project in a scientific context.

\section{Scientific Context}

\section{Interpersonal Violence}

Interpersonal violence - witnessing domestic violence, child maltreatment, school bullying, teen dating violence and date rapes - can bring on PTSD symptoms that may become chronic, or remain an "active" risk factor for later onset of post-traumatic stress (Wekerle \& Wall, 2002; for a meta-analytic review see Brewin, Andrews, \& Valentine, 2000). Trauma researchers suggest that early exposure increases the risk for developing post-traumatic stress beyond the risk associated with other traumatic experiences like motor vehicle accidents, natural catastrophes, and other life stressors (e.g. Kilpatrick, Acierno, Saunders, Resnick, Best, \& Schnurr, 2000). It is the interpersonal nature of the violence, especially when a caregiver or attachment figure is involved, that render it a "high impact" event that challenges coping and long-term adaptation.

\section{Post-traumatic Stress Disorder (PTSD) Symptoms}

The purpose of the study is not to diagnose students with the psychiatric disorder of PTSD, but instead to show that greater levels of symptom severity might be driving alcohol misuse behaviour, since alcohol may be used as a means of "self-medicating" the unpleasant emotions and memories that result from the trauma. Therefore, although the term 'PTSD symptoms' is used throughout this paper, the results of the study cannot be used to diagnose students with the actual disorder.

PTSD $^{3}$ is a complicated disorder that is precipitated by exposure to a traumatic stressor. The Diagnostic and Statistical Manual-IV (APA, 1994) defines a traumatic stressor as any event that is experienced or witnessed that involves actual or threatened death/ serious injury, or a threat to the physical integrity of the self or another, and is accompanied by a sense of fear, helplessness, or horror. The disorder is marked by three key symptom clusters that persist for longer than one month: 1) re-experiencing the traumatic event through intrusive thoughts, nightmares and/or flashbacks; 2) emotional numbing and the avoidance of trauma related reminders; and 3) hyper-arousal, including hyper-vigilance (i.e., over-scanning the envi- 
ronment for signals of danger or threat) and increased physiological arousal (e.g., difficulty calming, sleep problems, restlessness). As interpersonal violence can be a risk factor for the development of PTSD, current research indicates that having PTSD symptoms can be a risk factor for alcohol misuse.

\section{Alcohol Misuse and Post-traumatic Stress}

Much of the research indicates that PTSD and alcohol and other substance abuse commonly occur together in the same individuals and that this co-occurrence is far more common than can be explained by chance alone (Stewart, 1996; Wekerle \& Wall, 2002). For example, in a national probability sample of 3,906 adolescents, Kilpatrick et al. (2003) found that the prevalence rate for having PTSD with a substance abuse disorder $(\mathrm{n}=50)$ was almost the same as the base rate for PTSD alone $(n=55)$. Furthermore, from that same study, sexual assault, physical assault, and witnessing violence were all variables that increased the risk for a diagnosis of co-morbid PTSD and substance abuse. Given the co-occurrence of PTSD with alcohol and other substance misuse, researchers have posited several possible causal pathways to explain their relationship.

\section{Pathways Connecting PTSD and Substance Misuse}

There are three major hypotheses that attempt to explain the link between PTSD and substance misuse ${ }^{4}$. The high-risk hypothesis suggests that misusing substances elevates the risk of exposure to trauma (and thus of developing PTSD) due to a "dangerous/risky lifestyle.' The susceptibility hypothesis suggests that the misuse of substances can cause physiological and neurochemical changes that make an individual more susceptible to developing PTSD following exposure to a trauma (Brown \& Wolfe, 1994). The third and presently best-supported view is the self-medication hypothesis (De Bellis, 2002; Chilcoat \& Breslau, 1998; Stewart, 1996).

The self-medication hypothesis reasons that central nervous system depressants like alcohol, cannabis, opioids, and benzodiazepines may help reduce certain fear/startle responses, as well as the intrusive memories that are characteristic of PTSD. People suffering PTSD, having experienced symptom relief with substance(s) use, come to expect that it may relieve suffering, and are then motivated to engage in continued substance use to manage their PTSD symp- toms. Although there is substantial empirical support for the self-medication theory as it relates to explaining the relation of PTSD with alcohol abuse, it is currently recognized that the self-medication explanation is overly simplistic (Stewart, 1996). For example, alcohol and other drugs may control certain PTSD symptoms in the short term, but once the effects of the substance have worn off, the PTSD symptoms return. Furthermore, sometimes when symptoms return, they return in even greater severity due the physiological after-effects of substances like alcohol. Particularly, hyper-arousal symptoms can return with even greater severity due to the physiological arousal resulting from substance withdrawal (Jacobsen, Southwick, \& Kosten, 2001). It has also been suggested that alcohol can interfere with the body's natural habituation to traumatic memories (De Bellis, 2002). Thus, through a process of mutual maintenance, substance misuse can actually serve to maintain PTSD symptoms in the longer term creating a "vicious cycle" between PTSD symptoms and substance misuse. Although our study does not examine symptom severity across time, and therefore does not allow us to test a mutual maintenance hypothesis, the variables we are collecting data on do allow us to explore a self-medication model as it relates to the misuse of substances in young, potentially traumatized individuals.

Based on both community need and the best available empirical information, we have hypothesized, in accordance with the self-medication hypothesis, that PTSD symptoms will mediate the relationship between childhood maltreatment and substance misuse in a community sample of adolescents. Information has been collected using self-report measures on exposure to violence (Childhood Experience of Violence Questionnaire, CEVQ; Walsch et al., in press ) posttraumatic stress symptoms (Child PTSD Symptom Scale, CPSS; Foa et al., 2003), depressive symptoms, (Centre for Epidemiological Studies Depression Scale, CESD; Radloff, 1977), alcohol related problems (Rutgers Alcohol Problem Index, RAPI; White \& Labouvie, 1989), and resiliency (Child and Youth Resilience Measure, CYRM; International Resilience Project, Dalhousie University).

The data collection for this study has been administered in groups, but various safeguards have been prearranged so as to ensure that the study is anonymous with respect to data privacy. An active informed consent was sought from the high school 
students who chose to participate in this study, while a passive consent process was used with parents. Based on both community relevance and scientific merit, we brought forward our research proposal to the larger body of community stakeholders, so as both to ensure their consent and to give them an opportunity to modify the proposed project in accordance with their needs.

\section{Ethical Approval and Community Consent}

\section{Ethical Approval}

In the summer of 2005, two variations of the same ethics proposal were submitted to both the Mi'kmaq Ethics Watch at Cape Breton University, and the Dalhousie Health Sciences Research Ethics Board (REB). Approval to conduct research was granted by the Mi'kmaw Ethics Watch in November of 2005 and by the Dalhousie REB in April of 2006. The project proposal that was originally presented to both ethics boards in the summer of 2005 was revised, based on community input (see Community Participation), with respect to what mental health related constructs were being measured, and both ethics boards were informed of and approved these amendments to the project.

As this project is school-based, feedback from the Dalhousie REB that concerned issues around the methodology of the study (e.g., using an active versus passive parental consent) were always first discussed with our school partners from both participating schools. Decisions that came from those discussions were then reported back to the Dalhousie REB both in the form of amendments to the ethics protocol, as well as in the form of letters of approval from the guidance counsellors of both Mi'kmaq high schools and their Director of Education for the community school board.

\section{Community Consent}

Although this section of the paper will outline the steps involved in establishing community consent, it is first necessary to specify whom we mean when we employ the term 'community'. When this paper refers to community, it is referring to those agencies or institutions whose service mandate, in one form or another, includes the health and well being of children/ adolescents that reside within the administrative jurisdiction of these agencies/institutions. For the purpose of this paper, 'community consent' shall be distinct from 'participant consent', in that the community had to first consent to participating in the collaborative research process as a whole, before participant consent could be sought from potential teen participants. The process of participant consent is described in the section entitled Study Implementation.

Seeing as how this is a school-based study, the primary community partners for this study were the First Nation School Board and the principals and guidance counselors of the community high schools. Furthermore, because this study includes questions that might prove upsetting to some students, and could lead to the disclosure of child maltreatment, our community partnership extended to the community Mental Health and Social Work Services (MH \& SWS $)^{5}$. We also gained the consent of other child / adolescent health and welfare related service providers (see below for a list).

Formal community contact began in the fall of 2005, where a joint community-research team was invited to present a research proposal to the community based collaborative and therapeutic team (Case Management) and the Inter-Agency, which jointly consist of representatives from the following service providers/institutions: Native Alcohol and Drug Abuse Counselling Association (NADACA), the Health Centre, Home Care, Mi'kmaq Family and Children's Services, the Regional Hospital's Child and Adolescent Services, the RCMP, as well as three schools under the jurisdiction of the School Board.

Representatives from the various agencies were given the opportunity to become active participants/ advisors in shaping the project by asking questions, voicing concerns, and suggesting modifications. Both groups requested updating throughout the various stages of research, and to deliver a full disclosure of the research results and recommendations that the community will be able to utilize in a productive manner. Furthermore, it was agreed that Mental Health \& Social Work Services be allowed to use the data from this study to hopefully increase their capacity to secure funding for issues and programming around dealing with the consequences of childhood maltreatment.

Critical to the study was gaining approval at an administrative level by individuals appointed to directorial positions by Chief and Council. The Director of Education was formally contacted in the fall of 2005, and her approval was immediate. The Director 
of Health was also contacted in the fall of 2005 , and she invited the lead researcher to present the study proposal to the Board of Health in the spring of 2006. After both the board - a body of 12 appointed community representatives that included 3 elders - and the Director of Health were satisfied that their questions and concerns had been met with appropriate responses, they approved the project. The Director of Health also desired projects updates and a disclosure of the results.

\section{Community Participation}

Our school partners have been crucial to the success of this study. Our "internal champion", had both passion for the content area, a job specifically to support teens, and was obtaining a graduate degree that included research (see Commentary, this issue, by Doreen Stevens). As someone born in the community, and a school/mental health professional of the community, she could often answer questions about the project from a position and perspective unavailable to university-based researchers. Such key community partners played a critical role in formulating a process of consent for students and parents that was both practical and ethically sound. While our school partners helped plan and concretize the methodological and ethical issues of the study, representatives from MH \& SWS had an influence on the scope of the project as a whole.

Based on the recommendation of the former Case Management Team coordinator who was also a psychologist for Mental Health and Social Work Services (MH \& SWS), the project was modified so as to also focus on resiliency. In addition to having information on exposure to violence and its possible consequences (e.g., PTSD symptoms), MH \& SWS staff were equally keen to know about those factors - whether they be personal, interpersonal, cultural, or community-based - that might be buffering or shielding certain adolescents from experiencing post-traumatic stress symptoms or depression, or misusing alcohol. This suggested addition to the project has had the further benefit of strengthening and extending the partnership between MH \& SWS and the academic community at Dalhousie, as the first author of the resiliency measure adopted for the study, Dr. Michael Unger (www. resilienceproject.org) from the Dalhousie School of Social Work, agreed to come to the community to deliver a workshop on the topic of resiliency. Further- more, based on the data sharing agreement with $\mathrm{MH}$ \& SWS, the research team decided to remove two measures that although of academic interest were of less tangible benefit to the community, and to replace them with a measure of depression.

Our rationale for including a measure of depression was based on both community need and empirical literature. The literature on the relationship between exposure to violence and depression, and the literature on substance misuse and co-occurring problems certainly supports enquiry into a mediational relationship between maltreatment, depression, and alcohol misuse within this community. For example, childhood exposure to violence is predictive of both subsequent major depression and PTSD (Kessler et al., 1997; Kendler et al., 2000). Furthermore, Hall and Farrell (1997) report that for those with alcohol problems, the most prevalent cluster of co-occurring disorders, next to anxiety disorders (where PTSD is classified as an anxiety disorder), are mood disorders like depression. Therefore, we reasoned that measuring a pathway from maltreatment through to alcohol misuse that only involves post-traumatic stress symptoms might be casting too small a net, but that if we included a measure of depression, we might be able to provide the community with a more complex view of the roots of adolescent alcohol misuse.

\section{Study Implementation}

After receiving both community consent and ethical approval (from the Mi'kmaw Ethics Watch and Dalhousie University REB) the study was implemented in April of 2006. As this is a school-based study, only adolescents attending either of the two high schools in the community were invited to participate. Originally, the study was to use an active parent/ guardian consent process in which parents/guardians would be mailed a consent form that they would then have to read, sign, and return (to the school). Only students whose parent/guardian returned the signed form would then be invited to participate in the study, at which point these students would then be eligible to give their own informed consent to participate in the study. However, the Dalhousie University REB was concerned about a possible sample bias, in that students who were being exposed to parental/guardian violence would be less likely to have parental consent to participate in the study; thereby, reducing the value of the information obtained. This concern 
was reported back to our community partners, and with their support a passive parent/guardian consent process was proposed to the Dalhousie University REB, which they accepted once it was made clear that school personnel would use school records, school history, and professional judgment to assess whether or not students had the capacity to give informed consent themselves. It was decided that, for those students who were deemed ineligible to give their own informed consent, an informed parent/guardian consent process would be used.

In order not to be in conflict with the Mi'kmaq Ethics Watch provision that all children under the age of 14 need active parent/guardian consent before being invited to participate in research, we ensured that all student participants were at least 14 years of age. As the study uses questionnaires, students requiring the aid of an assistant for reading comprehension were not invited to participate, but an individual fluent in both English and Mi'kmaq was on hand at all times during data collection to assist in translation of key words if necessary.

Community stakeholders were given two weeks notice prior to data collection. At the same time, passive parental/guardian consent forms were distributed to the parents/guardians of all students under the age of majority by the schools. By way of the passive consent letter, parents/guardians were informed about the purpose, tasks, and risks of the study. They were made aware of the collaborative nature of the study, and were encouraged to call university-based researchers or the school staff should they wish to seek more information about the study, and/or to refuse to allow their child to participate in the study. No parents exercised their right to refuse to allow their child to participate in the study. On the day of data collection, the universitybased researcher reviewed the consent form with those adolescents that were eligible to participate in the study to provide them the opportunity to ask questions and ensure an informed process. Students who were not interested in participating in the study were free to leave at any time, and some students did choose this option, though records were not kept for how many students choose not to participate. Guidance counsellors and teachers were on hand during the administration of the questionnaires, and students were told that they could talk to their school's guidance staff at any point. Furthermore, MH \& SWS were informed well in advance about when data collection would take place, and this agency made arrangements to attend to any students who sought services as a consequence of participating in the study.

The questionnaires were administered in groups (organized by class/grade when possible). Students were informed that in order to increase their privacy, three different versions of the same survey package would be circulated. Due to the variable finishing times of the students who participated in the survey, there was no group debriefing. However, during the process of informed consent, students were made aware that they would have immediate access to the on hand guidance counsellors, and that other community services were ready to assist them on demand. Furthermore, all students received a 'help sheet' that was co-written by the primary investigator, MZ, and the former Case Management co-ordinator. Each help sheet included the name, summary statement, and contact information of support services that are both external (e.g., Kids Help Phone) and internal (e.g., MH \& SWS) to the community.

Students were informed that any information that they provided on the survey booklet or answer sheet would be anonymous, providing that they did not share their answers with anyone or write any personally identifying information on either the survey booklet or the answer sheet. They were also made aware that any information they did share with either researchers or the school staff would be kept confidential, unless it pertained to child maltreatment. It was made very clear to the students that if they did share information that pertained to child maltreatment, they would be interviewed in private so as to determine whether or not to report to the RCMP, the agency responsible for child protection. Based on an agreement between researchers and the schools, students were also informed that any information they shared with the researcher that pertained to child maltreatment would be shared with the guidance department of their school.

Given the group/classroom testing context, and the ways in which disclosures were made, verbal disclosures during testing were directed to a private discussion with the school guidance counsellor. Often, maltreated youth use humour to "test the waters" for tolerating personal information and to obtain some sense of mastery over an essentially hurtful and humiliating experience. One student, when reviewing a sexual abuse question, voiced a seemingly flippant remark about an example "like when you wake up 
and someone is on top of you?" The youth was told that that this comment may disturb other students for whom such an experience was true and the youth was subsequently asked to speak in private with the guidance counsellor. As that discussion proceeded, this particular youth disclosed his own maltreatment background. This was the only verbal disclosure of child maltreatment at either school that resulted immediately from the questionnaire completion. As the adolescent was over 15 years old, and the perpetrator was no longer connected to the family, a formal report was not filed. The adolescent did not wish to report the incident, nor did he seek further services from either the guidance counsellor or the community service providers.

There was one other incident that necessitated a follow up. A young adolescent woman had written her name on the survey package and asked for help. The researcher followed up on her request for help by way of a telephone call to her (via the school). The young woman assured him that she was not in any need of help, and that she felt that she could both depend on the school guidance counsellor for any problems that she might have, and that she also knew how to avail herself of the relevant community services. Outside of these two incidents, none of the adolescents who participated in the study demonstrated any signs of distress nor did they communicate any desire for a referral to any of the community service providers.

\section{Preliminary Findings}

Based on data we have obtained from 102 adolescent student participants who have completed the measures thus far, we are able to report the following associations between the variables measured in our school-based study. As can be seen in Table 1, the exposure to violence (CEVQ; Walsch et al., in press) total score is associated with post-traumatic stress (CPSS; Foa et al., 2003) symptom clusters, depression (CESD; Radloff, 1979), and problem alcohol use (RAPI; White \& Labouvie, 1989; e.g., missing school due to drinking). All measured aspects of maltreatment (emotional abuse, physical abuse, and sexual abuse) were associated with problem alcohol use ( $\mathrm{r}$ from +.24 to +.37 ). The exposure to violence total score was most strongly correlated with the following variables: the total PTSD score $(\mathrm{r}=+.36)$, PTSD-related avoidance $(\mathrm{r}=+.35)$, and problem alcohol use ( $\mathrm{r}$ $=+.26$ ). With respect to problem alcohol use (RAPI), both depression $(\mathrm{r}=+.47)$, and PTSD symptoms (total score) were related $(r=+.39)$. However, PTSD-related hyper-arousal had the strongest association with problem alcohol use $(\mathrm{r}=+.54)$. This suggests that the more agitated and restless the teen, the more likely they were to report problematic alcohol use.

Our measure of resiliency (CYRM, International Resilience Project, Dalhousie University, 2006), which includes personal, relational, community, and cultural aspects, was not related to any aspect of maltreatment. However, higher resiliency scores were associated with lower depression scores $(r=-.27)$, lower total PTSD symptoms $(\mathrm{r}=-.30)$, and lower PTSD avoidance / emotional numbing in particular $(\mathrm{r}=$ .41). These associations are particularly encouraging, especially since the avoidance symptoms of PTSD are most strongly associated with the development (Nemerhoff et al., 2006) and maintenance (Wenzlaff $\&$ Wegner, 2000) of PTSD symptoms. In other words, our findings can be interpreted to indicated that resilient adolescents are less likely to suffer depression or PTSD symptoms, and that furthermore, resilient adolescents are less likely to avoid reminders of a trauma (e.g., places where they were abused), which may facilitate their recovery following exposure to a traumatic event. Surprisingly though, higher scores on resiliency were not associated with fewer alcohol related problems. In our planned future analyses, a more thorough exploration of the CYRM's component parts might shed some insight into whether certain aspects of resiliency (e.g., relational) may indeed be protective from problem drinking. Developing resiliency early in childhood may be one prevention strategy for teen mental health, particularly, to the degree that PTSD and depression promote problem alcohol use as suggested here, a focus on enhancing youth resilience may be effective in the longer term in preventing escalation of alcohol use.

Although it is too early to come to any firm conclusions, it is encouraging for our mediational analysis that maltreatment and PTSD symptoms (particularly the hyper-arousal scale) are positively related to problems related to alcohol use, as both of these relationships are necessary precursors to demonstrating statistically that PTSD might be mediating the relationship maltreatment and alcohol misuse. Such a finding would direct practice to target PTSD symptoms as a more direct route for reducing or intervening early with alcohol abuse. These are promising 
times for youth intervention, as the one key program - Trauma-Focused Cognitive Behavioral Therapy (TF-CBT) - is available to all practitioners free on a web training site. To date, over 5,000 therapy students and health care professionals have been certified with TF-CBTWeb (see www.musc.edu/tfcbt and, to register for the course, www.musc.edu/tfcbt and click the Register tab). While there is presently no treatment efficacy data on this training program, those that complete the program demonstrate an increase in TF-CBT based knowledge, and prospective studies are being planned for the future.

We remain confident that in addition to providing workshops and training opportunities to community service providers, we will also be able to deliver information from this project that can be used to develop ideas around prevention and intervention that are commensurate with the community's needs and resources. Thus, the community can be ensured that our mutual goal of creating a truly collaborative relationship that has the best interests of the community at heart will be achieved.

\section{Endnotes}

1. Childhood maltreatment is defined as experiences that were witnessed or direct victimization in terms of sexual, physical, emotional abuse and neglect. In this study, childhood refers to the teens' lifetime experience of maltreatment, including witnessing domestic violence. The measure used here, however, did not tap neglect.

2. There is no collaboration between the RCMP and the research team with regards to the present schoolbased study, though the RCMP was made aware of the study through contact with the community Inter-Agency.

3. Although the literature cited for this section typically focuses on PTSD, recent theory on the biological workings of responding to stress have emphasized post-traumatic stress symptoms over the disorder (e.g., DeBellis, 2002). Similarly, our work is consistent with this view in that we are examining post-traumatic stress reactions across a continuum that ranges from lower levels of symptom severity to higher levels of symptom severity, instead of taking a categorical approach where individuals either have the disorder or do not have the disorder.

4. Although our study's emphasis is on alcohol use/ misuse and problems that follow from its misuse, the empirical literature suggests that substances other than alcohol (e.g., benzodiazepines, like Ativan or Valium) have a high co-occurrence with PTSD (Jacobsen, Southwick, \& Kosten, 2001), and therefore, this section employs the more general term substance misuse.

5. Though the original MH \& SWS supporters of the project-the director and psychologist-are no longer with MH \& SWS (due to retirement and relocation, 
respectively), the new acting director continues to support the study.

\section{References}

American Psychiatric Association. (1994). Diagnositic and statistical manual of mental disorders (4th ed.). Washington, DC: Author.

Blackstock, C., Trocmé, N., \& Bennett, M. (2004). Child maltreatment investigations among Aboriginal and Non-Aboriginal families in Canada. Violence Against Women, Special issue: Transnational and Cross-Cultural Research on Family Violence, Part II: Intervention Studies, 10, 901-916.

Brewin, C. R., Andrews, B., \& Valentine, J. D. (2000). Meta-analysis of risk factors for posttraumatic stress disorder in trauma exposed adults. Journal of Consulting and Clinical Psychology, 68, 748-66.

Brown, P. J., \& Wolfe, J. (1994). Substance abuse and post-traumatic stress disorder comorbidity. Drug and Alcohol Dependence, 35, 51-59.

Bureau of Statistics (1993). 1991 Aboriginal peoples data Northwest Territories - language, health status, and social issues. Northwest Territories.

Chilcoat, H. D., \& Breslau, N. (1998). Posttraumatic stress disorder and drug disorders: testing causal pathways. Archives of General Psychiatry, 55, 913-917

Comeau, M. N., Stewart, S. H., \& Collins, P. (2004). A qualitative study of self-perceived reasons for drinking a sample of high personality risk First Nation adolescents: Implications for early intervention. Mega-Net conference: CIHR "Violence, Gender, and Health Workshop", York University, Toronto.

Comeau, N. M., Stewart, S. H., Musquash, C., Wojcik, Bartlett, C., Marshall M., Young, J., \& Stevens, D. (2005). Community collaboration in developing a culturally relevant alcohol abuse early intervention program for First Nation youth. Ontario Association of Children's Aid Societies Journal, 49, 35-41.

De Bellis, M.D., (2002). Developmental traumatology: A contributory mechanism for alcohol and substance use disorders. Psychoneuroendorcrinology, 27, 155-170.

Foa, E. B., Johnson, K. M., \& Feeny, N. C. (2001). The child PTSD symptom scale: a preliminary examination of its psychometric properties. Journal of Clinical Child Psychology, 30, 376-384.
Hall, W., \& Farrell, M., (1997). Comorbidity of mental disorders with substance misuse. British Journal of Psychiatry, 171, 4-5.

Health Canada. (2003). A statistical profile on the health of First Nations in Canada. Ottawa: First Nations and Inuit Health Branch.

Indian and Northern Affairs Canada (1996). Report of the Royal Commission on Aboriginal Peoples Vol. 1, Part II, Chapter 10 - Residential Schools. Canada: http://www.ainc-inac. gc.ca/ch/rcap/sg/sgm10_e.html

Indian and Northern Affairs Canada (2004). Social Development: Health and Social Indicators Fact Sheet. Canada: http://www.ainc-inac. gc.ca/gs/soci_e.html

International Resilience Project, Dalhousie University (2006). www.resilienceproject.org

Jacobsen, L. K., Southwick, S. M., \& Kosten, T. R. (2001) Substance use disorders in patients with posttraumatic stress disorder: A review of the literature. American Journal of Psychiatry, 158, 1184-1190.

Kilpatrick, D.G., Acierno, R., Saunders, B., Resnick, H.S., Best, C.L. \& Schnurr, P.P. (2000). Risk factors for adolescent substance abuse and dependence: Data from a national sample. Journal of Consulting and Clinical Psychology, 68, 19-30

Kilpatrick, D.G., Ruggiero, K.J., Acierno, R., Saunders, B., Resnick, H.S., \& Best, C.L. (2003). Violence and risk of PTSD, major depression, substance abuse/dependence, and comorbidity: Results from the National Survey of Adolescents. Journal of Consulting and Clinical Psychology, 71, 692-700.

Kendler, K.S., Bulik, C.M., Silberg, J., Hettema, J.M., Myers, J., \& Prescott, C.A. (2000). Childhood sexual abuse and adult psychiatric and substance use disorders in women: An epidemiological and co-twin control analysis. Archive of General Psychiatry, 57, 953-959.

Kessler, R. C., Davis, C.G., \& Kendler, K.S. (1997), Childhood adversity and adult psychiatric disorder in the US National Comorbidity Survey. Psychological Medicine, 27, 1101-1119.

Mushquash, C. J., Comeau, M. N., \& Stewart, S. H. (2007). An alcohol abuse early intervention approach with Mi'kmaq adolescents. First Peoples Child \& Family Review, 3, (17-26) 